\title{
Tellurium purification: various techniques and limitations
}

\author{
D S PRASAD, CH SUDHEER, $N$ R MUNIRATHNAM* and T L PRAKASH \\ Centre for Materials for Electronics Technology, IDA Phase II, Cherlapally, HCL (PO), Hyderabad 500 051, India
}

\begin{abstract}
Limitations and techniques to purify tellurium metal especially using non-chemical techniques such as vacuum distillation and zone refining are discussed. It was found that the clean environments, design, handling and cleaning of quartz ware are equally important in achieving the desired purity levels.
\end{abstract}

Keywords. Tellurium purification; vacuum distillation; zone refining.

\section{Introduction}

Majority of semiconductor crystal properties prepared by tellurium and cadmium are known to have strong harmful influences by the presence of trace level concentration of residual impurities since they reduce substantially detector efficiency (Sahoo and Srikantiah 1996; Krinitsyni et al 2000). Purification steps of tellurium should minimize not only metallic, but also gaseous and gas-forming impurities. There are several purification methods established to obtain $6 \mathrm{~N}$ and above purity tellurium starting with a gross approach followed by more refined purification steps. The non-chemical routes usually followed to purify tellurium are vacuum distillation followed by horizontal zone refining (Kuchar et al 1996). Purification processes are normally carried out in clean area of different classes viz. 10000, 1000, 100, etc.

\section{Experimental}

The non-chemical process routes such as vacuum distillation and zone refining at our laboratory were carried out in clean area of class 10000 and laminar air flow benches of class 100 were used for material handling.

\subsection{Vacuum distillation}

The vacuum distillation assembly designed and fabricated at our laboratory is similar to the one described elsewhere (Mungekar et al 1973), except that the alumina cold fingers are four in number with a diameter of $\sim 24 \mathrm{~mm}$.

\subsection{Zone refining}

A zone refining equipment was fabricated and automated at our laboratory to work round the clock in programmable

\footnotetext{
*Author for correspondence
}

mode. The technical details are described elsewhere (Munirathnam et al 2001, patent to be awarded). Process parameters of zone refining require the investigation and optimization of many possible experimental conditions viz. quartz tube and boat and their cleaning methodology, ultra pure ambient gas, operating conditions such as speed of zone travel, ingot length/zone length ratio and zone temperature, which otherwise can act as limitations in achieving the required purity.

2.2a Quartz tube and boat: Usually quartz boat (GE 214 grade) is fabricated by closing both ends of the tube and then slit into two halves to form the boat shape of appropriate size. Slitting the quartz boat into two halves, cutting the ends of quartz tube from outward to inward (up to $\sim 30 \mathrm{~mm}$ long) with an angle of $45^{\circ}$ to the horizontal plane and covering those ends separately with two different pieces of planar quartz material of $0.5 \mathrm{~mm}$ more thickness than the tube has helped largely to reduce the breakages. This could be due to absence of weak surfaces during manufacture of the quartz boat. The quartz boat is shown in figure 1. Quartz tubes and boats used in zone refining are etched before loading tellurium metal by dipping in the mixture of aqua regia and $1 \%$ of $\mathrm{HF}$ in the ratio of $5: 1$ for about $60 \mathrm{~min}$ and rinsed with deionized water (DDW) 4 to 5 times. The parts were then dried with dry $\mathrm{N}_{2}$ gas jet.

2.2b Ultra pure ambient gas: Hydrogen gas (IOLAR2 grade) available through cylinders has oxygen, water, carbon dioxide, carbon monoxide, nitrogen and total hydrocarbons (THC) in unacceptable limits. When used in zone refining process, it has resulted in a black coloured powder of tellurium compounds on the surface of the tellurium metal bar. In our experiment hydrogen gas produced by electrolysis of nanopure water is used after passing through molecular sieve to remove oxygen and moisture. This procedure has facilitated in avoiding the impurities from the external sources. 


\subsection{Operating conditions}

A typical zone refined ingot in our experiment measures about $560 \mathrm{~mm}$ long with semicircular cross-section of $15 \mathrm{~mm}$ height with a mean width of $17 \mathrm{~mm}$. The ingot length $(L)$ to the zone length $(l)$ ratio was about $8 \cdot 3: 1$ with a zone speed of $30 \mathrm{~mm} / \mathrm{h}$. The tilt angle was calculated using the equation

$$
\theta_{\mathrm{c}}=\tan ^{-1}\left[2 h_{0}\left(1-d_{\mathrm{r}}\right) / l\right],
$$

where $h_{0}$ is the height of the ingot in solid, $l$ the zone length and, $d_{\mathrm{r}}$ the ratio of densities of liquid to solid tellurium (Pfann 1966). The zone temperature is maintained at $480 \pm 1{ }^{\circ} \mathrm{C}$ and a constant flow of hydrogen gas is maintained at around 50 PSI using a hydrogen generator cum purifier.

\section{Results and discussion}

Vacuum distillation is performed in vacuum $\left(\sim 2 \times 10^{-2}\right.$ torr $)$ at temperatures ranging from $450-800^{\circ} \mathrm{C}$. Impurities such as $\mathrm{Sb}, \mathrm{Bi}, \mathrm{Al}, \mathrm{Au}, \mathrm{Ag}, \mathrm{Cu}, \mathrm{Si}$ and $\mathrm{Fe}$ can be easily separated, whereas the removal of $\mathrm{Se}, \mathrm{As}, \mathrm{Na}, \mathrm{K}, \mathrm{Mg}$ and $\mathrm{S}$ is difficult (Kuchar et al 1996), because of their higher vapour pressure at that temperature. Among various types of cold fingers selected for deposition viz. stainless steel, quartz, copper and alumina, the last one is found to be most suitable. While the oxides present in tellurium at trace level wets quartz and stick upon freezing, the stainless steel and copper contaminate the deposit with impurities $\mathrm{Cr}, \mathrm{Ni}, \mathrm{Mo}, \mathrm{Fe}$ and $\mathrm{Pb}, \mathrm{Cr}, \mathrm{Ni}, \mathrm{As}, \mathrm{Fe}, \mathrm{Cu}, \mathrm{Sb}$, respectively in the range of 10-50 ppm (Mungekar et al 1973). Initial experiments showed that the deposition rate increases with time and reaches highest after optimum time of deposition and later becomes worst.

Since some of the impurities have the segregation coefficient, $K$, close to unity, tellurium is subjected to more than one zone refining cycle or operation viz. single (SZR), double (DZR), triple (TZR), and quadruple (QZR) zone refining, ensuring in each operation ultimate distribution is established (Bult et al 1987; Kuchar et al 1996). Also, optional zone lengths for all passes increase with segregation coefficient, but decrease with pass number (Chii-Dong et al 1998), suggesting zone length and number of passes are critical and play a major role in achieving purity. In our experiment, with a speed of $30 \mathrm{~mm} / \mathrm{h}$ and a zone width of $67 \pm 3 \mathrm{~mm}$, the results after QZR showed that $\mathrm{Al}, \mathrm{Mg}, \mathrm{Fe}$ reduced drastically from 10 to 1200 times when handled in clean area of class 10000 and in vertical laminar air flow benches of class 100. These values are estimated using inductive coupled plasma quadruple mass spectrometry (ICPMS). The above implies that the clean area can also act as a major limitation while purifying metals such as tellurium and cadmium. These results are tabulated in table 1.

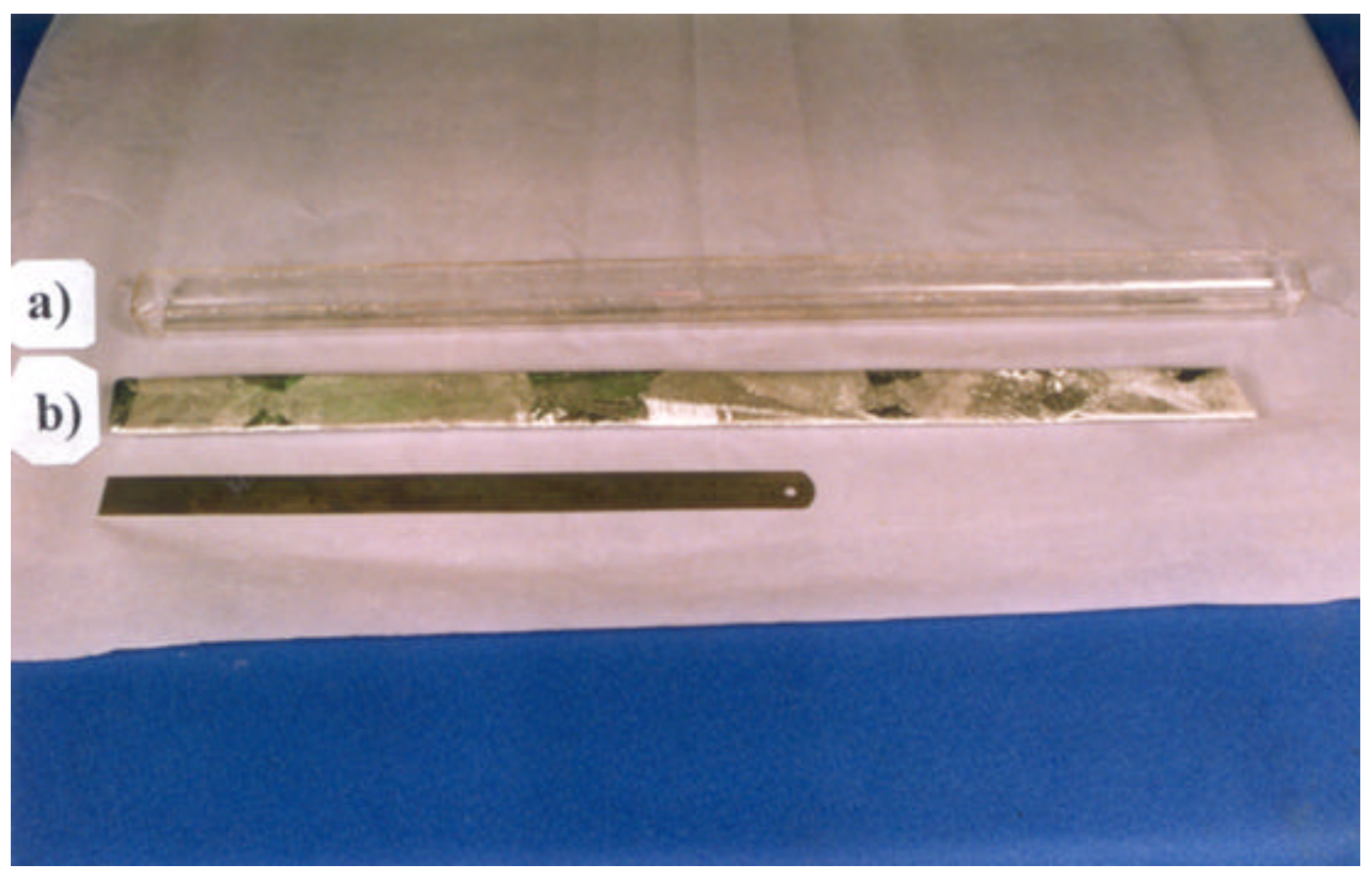

Figure 1. (a) Quartz boat used for tellurium zone refining and (b) the metal bar is of tellurium melted using quartz boat. Part of the material towards right end of the ingot is cut for analysis (A scale of $30 \mathrm{~cm}$ long is kept as marker). 
Table 1. Impurity levels in QZR tellurium metal in clean and non-clean environments.

\begin{tabular}{lccc}
\hline Element & $\begin{array}{c}\text { Non-clean } \\
(\mathrm{ppb})\end{array}$ & $\begin{array}{c}\text { Clean } \\
(\mathrm{ppb})\end{array}$ & $\begin{array}{c}\text { LOD } \\
(\mathrm{ppb})\end{array}$ \\
\hline $\mathrm{Al}$ & 550 & $<14$ & 14 \\
$\mathrm{Fe}$ & 2400 & $<2$ & 2 \\
$\mathrm{Mg}$ & 500 & $<2$ & 2 \\
\hline
\end{tabular}

\section{Conclusions}

In purifying tellurium to $6 \mathrm{~N}$ and above, some limitations in vacuum distillation and zone refining must be kept in mind. In addition to the process parameters in vacuum distillation such as temperature and pressure, the physical dimensions and material of construction of cold finger can act as limitation in increasing the purity and yield. Design of quartz boat in zone refining is important to reduce the breakages. Materials handling and cleaning procedures of quartz ware with ultrapure chemicals should be checked for less than ppt level trace impurities. Hydrogen ambient gas should be better than $7 \mathrm{~N}$ purity.
Clean bench of at least class 100 or better is mandatory to handle high pure metals.

\section{Acknowledgement}

The authors thank Dr B K Das, Executive Director, C-MET, for helpful discussion and encouragement.

\section{References}

Bult R P, Bollong A B I and Redden R F 1987 US Patent 4,690,725

Chii-Dong H, Ho-Meng Y and Tzuoo-Lun Y 1998 Canadian J. Phys. 76113

Krinitsyni P G, Popov S P and Chulzhanovi Y A 2000 Chem. Sustain. Devel. 8167

Kuchar L, Drapala J and Lunacek J 1996 J. Cryst. Growth 161 94

Mungekar D S, Ranade S N, Kunte S N and Rao G S 1973 Indian J. Technol. 1113

Pfann W G 1966 Zone melting (New York: John Wiley \& Sons, Inc.) 2nd edition

Sahoo D and Srikantiah R V 1996 Bull. Mater. Sci. 19483 